\title{
Diagnostic Evidence of Damage on Pecan Shells by Stink Bugs and Coreid Bugs
}

\author{
I.E. Yates \\ Russell Research Center Agricultural Research Service, U.S. Department of Agriculture, Athens, \\ GA 30613 \\ W.L. Tedders \\ Southeastern Fruit and Tree Nut Laboratory, Agricultural Research Service, U.S. Department of \\ Agriculture, Byron, GA 31008

\section{Darrell Sparks} \\ Department of Horticulture, University of Georgia, Athens, GA 30602 \\ Additional index words. Carya illinoensis, insects, shell punctures, stylet sheaths, electron microscopy, Hemiptera, \\ Pentatomidae, Coreidae

\begin{abstract}
Feeding activity by several species of phytophagous stink bugs and coreid bugs (Pentatomidae and Coreidae) on the fruits of pecan [Carya illinoensis (Wangenh.) C. Koch] causes severe economic losses in nut yield and kernel quality. Verification of late-season damage by these insects to pecan nuts has been possible only after examination of the condition of the kernel. Staining nuts with a red fluorescent tracing dye resulted in a differential contrast between the surface of the shell and sites of hemipteran punctures. This technique can be used with the aid of a dissecting microscope to identify hemipteran bug damage by examining the exterior of the shell. Stylet sheaths connecting the packing material on the shell interior to the seedcoat of the kernel have been identified and can be used as confirmatory evidence of hemipteran attack.
\end{abstract}

Stink bugs and coreid bugs [Hemiptera (Heteroptera)] attack many important agronomic and horticultural crops and weeds (Adair, 1932). Several species of hemipterans, including Nezara viridula (L.) (Demaree, 1922), Euschistus sp. (Turner, 1923), Leptoglossus phyllopus (L.) (Turner, 1923), and L. oppositus (Say) (Adair, 1932), attack pecans. These insects are among the most important insects on pecan because of the serious damage and losses they cause in nut yield and kernel quality. Total losses from Hemiptera during 1985 were estimated at 3.5 million dollars for the pecan industry in Georgia alone (Deuce and Suber, 1986). Damage in Georgia was severe, especially during the 1989 season.

Pecan fruits can be attacked by hemipterans during early season fruit development while the fruit is in the liquid endosperm stage (commonly called the water stage). Damage at this time results in a fruit disorder usually referred to as black pit or black heart. Several markers can be used to distinguish hemipteran damage at this stage, such as fluid seeping from inside the fruit and accumulating on the shuck (involucre) at the puncture site. The area surrounding a puncture site turns black within $1 \mathrm{~h}$, the entire vascular system between the shuck and shell darkens within 2 days, and the interior of the nut blackens and fruits drop within 4 to 5 days (Woodroof and Woodroof, 1928). Shucks adhere tightly to the shell of fruits dropping from stink bug damage. In contrast, shucks are easily removed from the shell of fruits during the normal summer fruit abortions that are inherently characteristic of pecan (Adair, 1932). The summer drops referred to in this early work on black pit of pecan are more appropriately characterized as the third and fourth drops (Sparks

\footnotetext{
Received for publication 11 Apr. 1990. We gratefully acknowledge the assistance of Donnie Maxey and Joyce Lambert in the preparation of photomicrographs. Trade names are used in this publication to provide specific information. Mention of a trade name does not constitute a guarantee or warranty of the product or an endorsement by the USDA over other products not mentioned. The cost of publishing this paper was defrayed in part by the payment of page charges. Under postal regulations, this paper therefore must be hereby marked advertisement solely to indicate this fact.
}

and Madden, 1985). Another identifying characteristic of hemipteran damage to fruits in the water stage is the secretion in the pecan shuck of a stylet sheath (a thin casing of salivary material through which the insect probes the fruit) (Dutcher and Todd, 1983). However, this is detectable only by microscopic examination of shuck sections. Two other markers that distinguish the third and fourth drops from insect-induced abortions are evident (D.S., personal observation). The condition of the ovule is different in fruits aborting during the third and fourth drops vs. those dropping from insect damage. The ovules of fruits aborting in the former case are shriveled and yellowish, whereas the ovules of fruits injured by hemipterans are about normal in size and brown to brownish-black. Black streaks form on the shuck of insect-damaged fruits and the entire shuck eventually turns black, whereas the shuck on fruits aborting from the third and fourth drops remains green.

After the water stage, as kernel (seedcoat, embryo, and remaining endosperm) development progresses, hemipteran feeding can be ascertained only by cracking the nuts and examining the kernels (Polles, 1977). Feeding sites on kernels are characteristically brown to black spots that become sunken and pithy and are bitter to taste (Demaree, 1922). Consequently, these injuries commonly are called kernel spot (Moznette et al., 1940). The frequency of kernel spot ranged from $1.8 \%$ in nuts collected from trees treated with pesticide sprays to $5.8 \%$ in nuts from untreated trees (Payne and Wells, 1984). Feeding and oviposition punctures by the pecan weevil [Curculio caryae (Horn)] also cause discoloration of the kernel, but injury caused by this insect can be easily identified on the surface of the shuck or nut by 0.5 -mm-diameter circular holes through which the adult feeds on the kernel and oviposits. Even though anatomical characteristics of hemipteran punctures through the shucks of early season pecan fruits have been described (Dutcher and Todd, 1983), the anatomy of punctures through the shells of mature nuts has not been studied. Punctures through hardened shells of pecan nuts are microscopic, have no border necrosis, and are thus very difficult to observe. The objectives of the current study were to develop methodology to locate hemipteran punctures on the pe- 


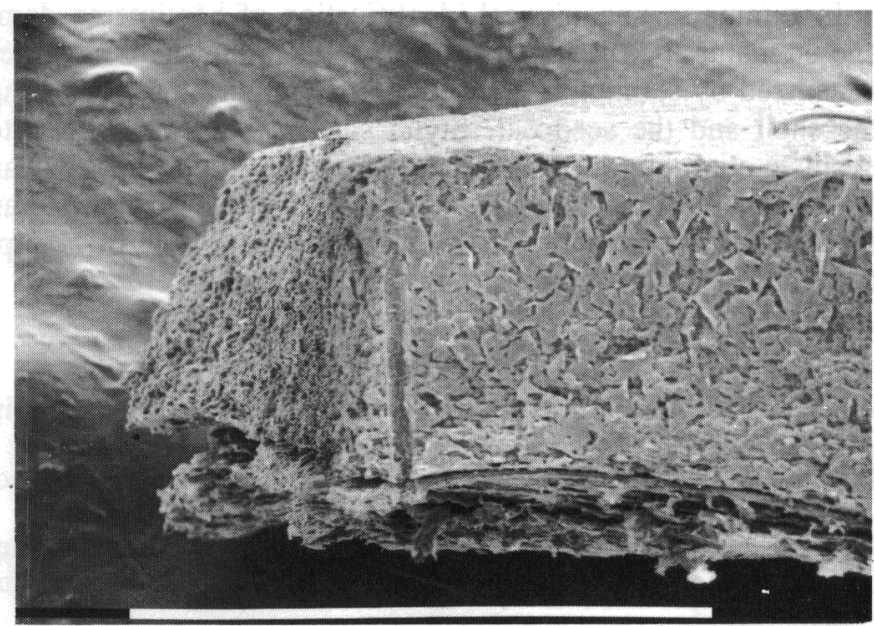

Fig. 6. SEM of shell section through hemipteran puncture site on shell suture line. Bar $=1.0 \mathrm{~mm}$.

intact when the nuts were cut in cross section with the saw (Fig. $3)$. When the portion of the sheath connecting the shell to the seedcoat was lost, the red stain migrated through the stylet sheath in the shell, diffusing out into the packing material (Fig. 4) and making a 1- to 2-mm-diameter spot that was visible without magnification. When the portion of the sheath connecting the shell to the seedcoat was intact, the stain would often penetrate through the insect's stylet sheath to the seedcoat, again diffusing out to create a 1 - to $2-\mathrm{mm}$ red spot that was visible without magnification.

A stylet sheath can be likened to a pipe connecting the inner wall of the shell to the seedcoat. Infrequently, sheaths were found still attached to both the shell and the seedcoat. Most often, however, they were attached only to either the packing material on the inner surface of the shell (Fig. 3) or the seedcoat. Usually the sheath had separated from the shell or the seedcoat, apparently the result of shrinkage of the drying kernel.

SEM of hemipteran damage to pecan nuts. The puncture site on the shell observed by SEM indicated deposition of salivary material in a flange surrounding the point of stylet entry (Fig. $5 \mathrm{a}$ ). The diameter of the opening was typically $\approx 50 \mu \mathrm{m}$ or $\approx 0.1$ the diameter of a weevil feeding puncture. On another shell in which the salivary material was missing, the outermost layer of the shell appeared to be degraded (Fig. 5b). A thin bridge of salivary material commonly was observed across the puncture site when examined from the outside of the shell. Examination of the interior of the puncture through the shell demonstrated that the salivary material formed a stylet sheath that was constructed in a concentric ring configuration (Fig. 5c). The diameter of the puncture through the packing material on the inside of the shell was $\approx 50 \mu \mathrm{m}$ (Fig. $5 \mathrm{~d}$ ), the same dimension as on the outside of the shell (Fig. 5a). The hemipteran puncture formed a cavity in the shell (Fig. 6). This portion of a hemipteran feeding tract in a mature pecan nut typically was not observed to show any evidence of deviating from the plane of attack; that is, although the feeding tract may not be perpendicular from the site of puncture to the kernel, the feeding tract was linear from the puncture site to the kernel.

Once the hemipteran has pierced the shell, continuation of the stylet sheath was deposited in the empty space between the shell and seedcoat. In this empty space, there are no constraints of adjacent tissues as in the shell. The stylet sheath was white in unstained specimens and could be easily distinguished by
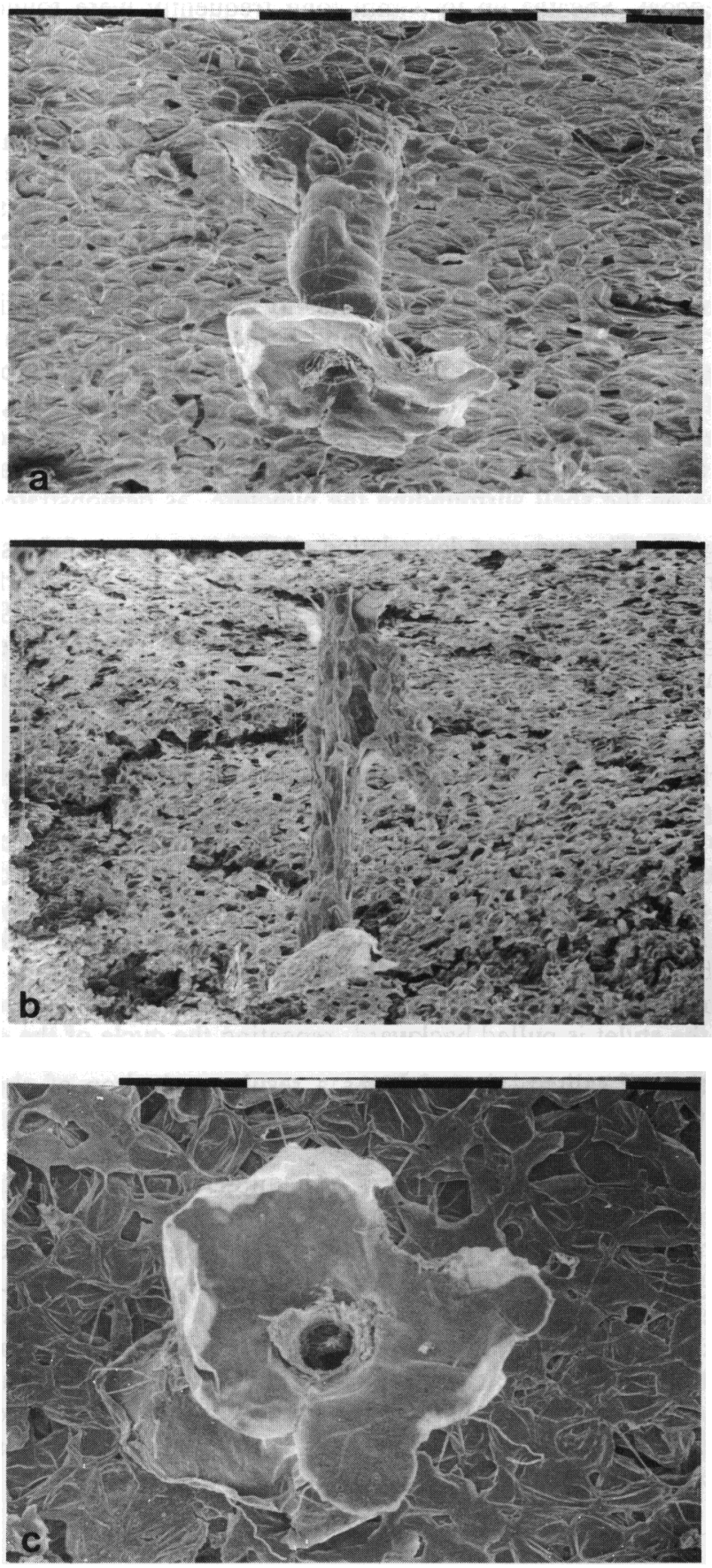

interior. (a) Unbranched. Bar $=0.1 \mathrm{~mm}$; (b) branched. Bar $=1.0$ $\mathrm{mm}$; (c) presumed site of attachment to seedcoat. Bar $=0.1 \mathrm{~mm}$.

observation with a dissecting microscope, as in Fig. 3. However, the elaboration of the stylet sheath was more easily determined by observation with the SEM. The gross morphological structure of the stylet sheath was columnar (Fig. 7a). This portion of the stylet sheath may branch along the periphery (Fig. $7 b)$. The interior of the stylet sheath extending from the shell to the kernel had the same appearance of being deposited in concentric rings as that observed in the shell. The flattened expansion at the end of the sheath serves as an attachment of the sheath to the seedcoat (Fig. 7c). The length of the sheath was determined by the distance between the inner shell and the 
seedcoat. Sheaths up to $3 \mathrm{~mm}$ long frequently were found in nuts with inferior kernel development.

\section{Discussion}

Hemipteran punctures to pecan fruits after kernel maturation can occur before or after the shuck has separated from the nut but before shuck dehiscence (Polles, 1979). In the cases of attack after the shuck has separated from the nut, the stylet of the hemipteran passes through the empty space between the shuck and nut in a fashion similar to what we have described for the area between the shell and kernel. The hemipteran deposits salivary material in this space to form an entry site to the nut (W. L. T., personal observation). As the shuck dehisces, the sheath attachment to the shuck is broken. The break may occur at the outer surface of the shell, accounting for the degraded area on the shell surrounding the puncture, as demonstrated in Fig. 5b. The apparent degradation of the outer layer of the shell surface when the sheath is pulled away from the shell surface may be attributed to the chemistry of the sheath. Miles (1968) proposed that the fatty acid residues found in sheath material may partially dissolve the waxy coating on plant structures. Breaks at the shell surface leave the shell puncture open.

The concentric ring configuration of the internal sheath material (Fig. 5c) suggests that 'the sheath of stink bugs and coreid bugs is constructed similar to aphid sheaths (Miles, 1968, 1972). To penetrate plant tissues, the aphid stylet moves in a series of backward and forward motions. On a backward motion, a drop of sheath material is secreted and begins to gel immediately. A drop of saliva is then, ejected into the sheath material, making it balloon out. Next, the stylet is thrust forward through this drop, piercing the encl.-Another drop of sheath material is ejected as the stylet is pulled backward, repeating the cycle of the deposition of salivary material. As a result, each drop of sheath material is in contact with the one secreted previously, creating the appearance of concentric rings.

We have pinpointed markers of hemipteran damage to pecan nuts other than the standard assessment based on kernel discoloration. In advanced cases of deterioration resulting in irregularly shaped lesions (Fig. 1), kernel discoloration is an ambiguous characterization that conceivably could result from other causes, such as contamination by microflora. Therefore, a more valid, distinguishable marker is required. There is a delay between the time a hemipteran punctures the kernel and the occurrence of darkened discoloration (Turner, 1923). As a result, detection of kernel damage is delayed.
In summary, unequivocal identification of hemipteran damage on mature pecan nuts is possible by locating shell punctures visualized by staining and by finding stylet sheaths connecting the shell and the seedcoat. Stylet sheaths have been used to evaluate stink bug attack of rice (Bowling, 1979) and soybean (Bowling, 1980). These anatomical evidences of hemipteran feeding should facilitate studies to evaluate the role of hemipteran attack in late-season pecan kernel disorders.

\section{Literature Cited}

Adair, H.S. 1932. Black pit of the pecan and some insects causing it. U.S. Dept. Agr. Bul. 234.

Bowling, C.C. 1979. The stylet sheath as an indicator of feeding activity of the rice stink bug. J. Econ. Entomol. 72:259-260.

Bowling, C.C. 1980. The stylet sheath as an indicator of feeding activity by the southern green stink bug on soybeans. J. Econ. Entomol. 73:1-3.

Demaree, J.B. 1922. Kernel-spot of the pecan and its cause. U.S. Dept. Agr. Bul. 1102.

Deuce, G.K. and E.F. Suber. 1986. Summary of losses from insect damage and costs of control in Georgia, 1985. Univ. of Georgia Spec. Publ. 55.

Dutcher, J.D. and J.W. Todd. 1983. Hemipteran kernel damage of pecan. Miscellaneous Publ. Entomol. Soc. Amer. 13:1-11.

Miles, P.W. 1968. Insect secretions in plants. Annu. Rev. Phytopath. 6:137-164.

Miles, P.W. 1972. The saliva of Hemiptera, p. 183-255. In: J.E. Treherne, M.J. Berridge, and V.B. Wigglesworth (eds.). Advances in insect physiology. Academic, New York.

Moznette, G. F., C.B. Nickles, W.C. Pierce, T.L. Bissell, J.B. Demaree, J.R. Cole, H.E. Parson, and J.R. Large. 1940. Insects and diseases of the pecan and their control. U.S. Dept. Agr. Farmers Bul. 1829.

Payne, J.A. and J.M. Wells. 1984. Toxic penicillin isolated from lesions of kernel-spotted pecans. Env. Entomol. 13: 1609-1612.

Polles, S.G. 1977. Black pit and kernel spot of pecans: Special emphasis on southern green stinkbug. Proc. Southeastern Pecan Growers Assn. 70:47-52.

Polles, S.G. 1979. Black pit and kernel spot of pecans: Special emphasis on southern green stinkbug. Proc. Georgia Pecan Growers Assn. 10:29-37.

Sparks, D. and G.D. Madden. 1985. Distillate flower and fruit abortion as a function of cultivar, time, and pollination. J. Amer. Soc. Hort. Sci. 110:219-223.

Turner, W.F. 1923. Kernel spot of pecan caused by the southern green soldier bug. J. Econ. Entomol. 16:440-445.

Woodroof, J.G. and N.C. Woodroof. 1928. The dropping of pecans. Natl. Pecan Growers' Assn. Bul. 2(1):28, 30-34. 